simple relation affords a sufficient answer to all questions which might be put in reference to the affections of the brain, of the lungs, of the stomach, \&c. I shall only state, in general terms, that the pathological phenomena during life were not of such intensity as the post-mortem examination would suggest.

German Hospital, Dalston, 1849.

\section{ON CERTAIN IMPORTANT POINTS IN THE CHEMISTRY \& PATHOLOGY OF THE URINE.}

BY AR'THUR HILL HASSALL, M.B.

$$
\text { (Continued.from } p \text {. 608.) }
$$

On the Presence of Oxalate of A mmonia in the Urine.-This important salt is very generally, if not constantly, present in the urine; it is to be detected more by its own proper tests than by the form of crystal, which is subject to many modifications liable to be confounded with those of other saline urinary compounds.

I have ascertained that it very generally enters into the composition of the soluble dumb-bells already described; in some cases, indeed, these would appear to be entirely formed of this oxalate.

On the Presence of Oxalurate of Ammonia-Oxalate of ammonia and urea evince considerable affinity for each other, and enter readily into combination, in which state they may be frequently detected in the urine.

On Urea-Chloride of Sodium.-Chloride of sodium and nrea also manifest a strong affinity for each other, and form, when dried, crystalline compounds, which are very frequently encountered in the urine under different modifications.

On Urea-Chloride of A mmonia.-Hydrochlorate of ammonia and urea very readily combine with each other, and the compound may be easily prepared artificially.

I have not as yet succeeded in identifying it in the urine; there is scarcely a doubt, however, but that it is sometimes present in that fluid.

I have many observations and drawings illustrating various particulars connected with the above general facts.

Notting-hill, Dec, 14, 1849.

(To be continued.)

\section{ON LACERATION OF THE PERIN AUM. BY ROBERT BARNES, M.D., London.}

I OBSERVE, in The LANCET of May $26 \mathrm{th}$," an interesting account of a case of lacerated perinæum, and cure by the twisted suture, by Mr. Rogers. I take the liberty of offering a few observations on the subject, because I believe that the method pursued in that case, although, fortunately, successful, is not by any means the best calculated to repair the distressing injury in question.

Other cases besides that of Mr. Rogers have long removed all doubts as to the possibility of cure in similar cases, but it should also be remembered, that repeated failure of the twisted quill, and other forms of suture, has rendered the prospect of recovery under their use extremely discouraging. When we reflect upon the extent of the surfaces to be maintained in apposition, the almost constant motion of the two sides of the peringeum, and the unavoidable irritation produced by the passage of urine, fæces, and discharges from the uterus and vagina, it is no matter for surprise, that in Mr. Rogers's first attempt, at the "end of five days he found that the two stitches had ulcerated through, and that the fissure was as bad as ever." I have witnessed several similar attempts which have issued in the same result. The second operation in which the twisted suture was used, is one which, when performed with great care, and under favourable circumstances, has occasionally been successful; and Mr. Rogers's case is valuable, as a fact in illustration. Still, I believe that no amount of skill and precautions will justify the surgeon, in the majority of cases, in looking for perfect union by means of any of the sutures in common use. Such has hitherto been the difficulty of completely restoring the perinsum to its original integrity, that surgeons have often been content to obtain a closure of the posterior half of the fissure; and an eminent obstetric author

* We offer an apology to Dr. Barnes for the long delay that has taken place before this paper was printed, If he saw the magnitude of the pile of communications before us, he would admit that our week'y task is one of both delicacy and difficulty, - ED. $L$. has sought to console his brethren under the disappointment of baffled art, by assuring them that it is better not to cure the whole laceration!

As I am unable to assent to this proposition, I feel it my. duty to call the attention of the profession to a proceeding which may relieve the surgeon from the necessity of adopting this unsatisfactory conclusion; - I allude to the application of the bead-suture of my colleague, Mr. Charles Brooke. This ingenious invention appears to me to fulfil all the conditions required by the complicated difflculties of the case. Perfeet apposition of the entire surfaces is made secure by the nature of the suture, which can be adapted to any point of the fissure both along the raphexternally, and within the vagina; there is little danger of the suture giving way by ulceration, as no strain ever comes upon the threads, but is spread over the smooth surface of the beads; and this circumstance is attended by the peculiar advantage of enabling the sutures to be retained long enough to ensure firm adhesion; the beads have also a great superiority over the needles, in maintaining deep pressure, a point of the utmost importance. The result of this perfect approximation is, that no lodgment is afforded for clots, pus, urine, or other irritating matters, to prevent union by the first intention throughout the entire extent of the wound.

Having recently attended a case of extensive laceration under very unfavourable circumstances, with Mr. Brooke, in which his suture was employed with the most perfect success, I am in a position to bear my unqualified testimony to the advantages of this proceeding. Having done this, I feel that it would be improper on my part to pursue the subject farther on the present occasion, either by examining the defects of the usual methods, or by describing minutely the operation of Mr. Brooke, or by giving the history of the interesting case to which I have referred. This duty more fitly devolves on the ingenious inventor, who, I trust, will shortly place before the profession, in a comprehensive manner, an account of the various operations he has contrived for the relief not only of laceration of the perinseum, but of the many other distressing and rebellious lesions to which the vagina and urethra are exposed.

Gloucester-terrace, Hyde-park, 1849 .

\section{CASE OF STABBING; PROTRUSION OF OMEN-} TUM; STRANGULATION OF A PORTION OF INTESTINE; OPERATION AND RECOVERY. Reported by JAMES TEAGUE, M.R.C.S.Eng,
Blakeney, Gloucestershire.

ON Sunday, August 12th, at three A.M., I was called to attend a man named Richard $\mathrm{V}-$-, aged thirty, who, it was stated, had been stabbed in a brawl. I immediateily hastened to his house, about a mile distant, and upon examination discovered five wounds; one in the abdomen, three inches above the left ilium, two in the side, one in the arm, and another in the forehead; none of which, however, appreared of nuch importance except the first; but this was of a very serious description: it was about two inches in length; its direction was oblique, and from behind forwards, the anterior extremity being the deeper; out of this wound was protruding about two and a half inches of omentum, jagged and bleeding. Upon introducing my finger into the wound, I found the omentum very tightly constricted by the peritonæum, but conld discover no intestine bound in along with it. Under these circumstances, I determined to cut off the protruding portion of omentum, and allow the constricted part to remain as a plug, which wonld prevent hæmorrhage in to the peritonæum: this plan of action I considered better than to return the injured viscus into its cavity. Mr. Collins, of Newnham, whom I had previonsly sent for, now arrived, and coinciding with the view I had taken, I cut off the omentum on a level with the external oblique muscle, passed one suture through the integuments to keep them together, and applied a strap or two of adhesive plaster; no bleeding followed.

From the period he received the wound, which occurred about twelve o'clock the previous night, he had suffered excruciating pain, and had lost a considerable quantity of blood, which cansed him to faint several times before reaching his home, whither he was obliged to crawl upon his hands and knees; the exertion of doing so, probably causing so much omentum to protrude.

After the operation, I ordered him forty minims of tincture of opium, and left him at six o'clock much freer from 